\title{
Autoridade, presença e silêncio: os percursos criativos na obra de Jill Greenhalgh
}

Authority, presence and silence: the creative paths
in Jill Greenhalgh's work

Marisa de Souza Naspolini ${ }^{1}$ 


\section{Resumo}

Este artigo discute aspectos de parte da obra da diretora galesa Jill Greenhalgh, fundadora do Projeto Magdalena e ex-professora da Aberystwyth University, buscando observar os percursos por ela traçados na constituição de uma cena que se instala entre teatro e performance. Para tanto, analiso o processo criativo de três de seus trabalhos mais recentes, averiguando os procedimentos adotados na construção de uma tessitura cênica que utiliza o corpo como elemento poético central.

Palavras-chave: Presença; silêncio; corpo; performance; processo criativo

\section{Abstract}

This article discusses aspects of part of the work of the Welsh director Jill Greenhalgh, the Magdalena Project founder and former professor of Aberystwyth University, seeking to observe the paths she traces in the constitution of a scene that installs between theatre and performance. In order to do so, I analyze the creative process of three of her most recent works, investigating the procedures adopted in the construction of a scenic weaving that uses the body as a central poetic element.

Keywords: Presence; silence; body; performance; creative process 
Este artigo analisa aspectos de parte da obra de Jill Greenhalgh, buscando observar alguns dos elementos constitutivos de seu processo criativo, tendo o corpo como elemento fundante na constituição de uma cena que se situa entre o teatro e a performance. Greenhalgh é diretora, performer e atuou como professora do Departamento de Performance Studies da Universidade de Gales-Aberystwyth por 14 anos (2002-2016). Nos anos 1970/80, trabalhou como atriz no coletivo Cardiff Laboratory Theatre 2 , sob a direção de Richard Gough, e também com outros grupos experimentais de diferentes partes da Europa. Em 1986 ela fundou o Projeto Magdalena ${ }^{3}$ e passou a dedicar-se à sua difusão e crescimento, procurando interfaces entre sua própria produção artística (como diretora) e acadêmica. Ela também atua na organização de encontros, festivais e processos colaborativos no âmbito da Rede Magdalena. Neste artigo nos debruçaremos sobre algumas de suas encenações mais recentes: The Acts - Vigia (Os Atos - Vigia) (2006-2011), The Threat of Silence (A Ameaça do Silêncio) (2010-2012), que, juntamente com a produção mais recente (The Book of Space) (2014), integra a trilogia The Quietude Project (Projeto da Quietude), e Dohter (Filha) (2011), que permanece em repertório.

O trabalho de Greenhalgh circula por diversas categorias, como devised performance, teatro físico, encenação não textocêntrica, processo colaborativo, teatro visual e se constitui como uma interface entre teatro e performance. As imbricações entre esses dois formatos evidenciam um campo de fronteira "à medida que o teatro se aproxima cada vez mais de um acontecimento e dos gestos de auto-representação do artista performático", segundo Lehmann, que identifica nos anos 1980 uma "tendência à teatralização da arte performática". Em suas reflexões sobre a noção de teatro pós-dramático, ele afirma que a performance também se aproxima do teatro "ao explorar estruturas audiovisuais elaboradas, ao expandir o uso das tecnologias midiáticas e ao alargar seus processos no espaço e no tempo" (Lehmann, 2007, p. 223-224). Féral denomina esta tendência de "teatro performativo" e a define como um teatro que se distanciou da representação, que investe na "'vivacidade' (liveness) dos artistas", que "toca na subjetividade do performer" (Féral, 2008, p. 207). Greenhalgh usa o termo performance para se referir a seu próprio trabalho, admitindo as aproximações que estabelece com o campo do performativo, particularmente no que diz respeito a um tipo de ator que não representa, ao forte diálogo com o elemento visual, às interpenetrações entre real e fictício.

Suas performances consistem frequentemente em instalações de forte impacto imagético, unindo fragmentos de ação, som, silêncio e objetos para criar sequências

\footnotetext{
${ }^{2} \mathrm{O}$ Cardiff Laboratory Theatre, grupo de teatro experimental com base em Cardiff, País de Gales, foi fundado por Mike Pearson em 1974 e em seguida foi integrado também por Richard Gough. $\mathrm{O}$ grupo tinha forte referência no trabalho físico e realizou workshops e seminários internacionais com os principais encenadores e pesquisadores atuantes, como Grotowski, Barba, a Academia Ruchu e o Piccolo Teatro di Pontedera. Em 1982, Pearson e Lis Hughes Jones deixam o grupo e fundam o Brith Gof, com forte atuação na cena britânica. Gough permanece como diretor e transforma o acervo e as atividades do grupo em uma organização de maior porte que hoje constitui o CPR (Centre for Performance Research), centro de referência em publicações e arquivo documental sobre teatro e performance, sediado no País de Gales.

${ }^{3}$ O Projeto Magdalena (The Magdalena Project) é uma rede dinâmica de mulheres de teatro e performance, de caráter multicultural, que surgiu como um espaço de discussão, troca e apoio mútuo visando gerar visibilidade ao trabalho artístico de mulheres, hoje presente em aproximadamente cinquenta países. Desde sua criação, em 1986, no País de Gales, o projeto esteve engajado em fomentar a consciência da contribuição das mulheres para o teatro e em apoiar a exploração e a pesquisa através de uma oferta concreta de oportunidades de intercâmbio, agregando praticantes das artes da cena de várias partes do mundo, sejam companhias, artistas individuais ou acadêmicas, que encontram ali um espaço crítico de discussão e reconhecimento do seu trabalho.
} 
e formas que, nas suas palavras, possam "romper, desafiar, refletir ou resistir às expectativas e rotinas da vida cotidiana". Ela fala sobre o desejo "raramente satisfeito" de que suas performances sejam atos de resistência contra o status quo e contra a repressão cotidiana aos "sonhos das crianças e à imaginação dos adultos que acreditam no impossível" (Greenhalgh, 2006, p. 31). Em seus trabalhos mais recentes, Greenhalgh tem perseguido o silêncio. Silêncio como construção artística. Silêncio como estratégia de discurso. Silêncio que permite a criação de um refúgio para o bombardeamento cotidiano de barulho e informação e que busca na cena um lugar de reflexão. Susan Sontag diz que o silêncio existe como uma decisão. Para John Cage, "não há silêncio; pois sempre há som. O que há são sons intencionais e sons não-intencionais; som e silêncio em constante mutação e interpenetração"4 (Heller, 2011, p. 18).

A busca pelo silêncio, pela economia do gesto, pela interpretação precisa e minimalista, pela forma frugal do "menos é mais", revela um desejo de criação que passa pelo descondicionamento de formas afetadas e por uma tentativa de zeramento, respiro, pausa. O silêncio tem sido usado com frequência na produção teatral contemporânea como forma de resistência a uma banalização da linguagem e ao apelo excessivo dos meios de comunicação de massa. O pesquisador Cassiano Quilici, em um artigo intitulado "Teatros do silêncio", discorre sobre o prestígio que o silêncio adquiriu junto a diversos criadores ao longo do século XX que optaram pela não verbalização como forma de fugir dos clichês e da banalização na arte. Ele se remete a experiências extremas do absoluto nas tradições místicas, tanto orientais quanto ocidentais, para refletir sobre o papel que o silêncio vem adquirindo em um mundo marcado pelo relativismo. Do "não-dito" em Tchécov ao "vazio" em Artaud, passando pelas imagens corporais de Meyerhold e pelo misticismo de Grotowski, o autor propõe pensar "as retóricas do silêncio" não apenas como "limite da linguagem" mas como fronteiras entre as linguagens, que podem propiciar experiências profundas que buscam novos modos de afetar o espectador (Quilici, 2005). Sontag também se refere ao silêncio e outras ideias afins, como vazio, redução e "grau zero", como noções fronteiriças que podem ser consideradas os principais termos de uma retórica espiritual e cultural particular. Para ela,

[...] as noções de silêncio, vazio, redução esboçam novas formas de olhar, ouvir, etc. - especificamente, seja para ter uma experiência mais imediata, sensual de arte ou para encarar o trabalho de arte de uma forma mais consciente, conceitual (Sontag, 1981, p. 6)

Em um artigo publicado na Revista Open Page Theatre-Women-Struggle (2004), Greenhalgh fala de sua opção pelo silêncio como ligada a um cansaço com o excesso de palavras que domina a cena. E propõe um exercício de imaginar o mundo sem palavras por uma semana. Seria um paraíso ou um inferno? Que outras formas de comunicação emergiriam? Talvez o espaço vazio criado pela ausência das palavras revelasse um território que já foi ocupado por nossos ancestrais, certamente mais

\footnotetext{
${ }^{4}$ Esta compreensão sobre o silêncio diz respeito a um dos momentos vividos pelo artista, entre as décadas de 1950 e 1960.

${ }^{5}$ No original: "The notions of silence, emptiness, reduction, sketch out new prescriptions for looking, hearing, etc. - specifically, either for having a more immediate, sensuous experience of art or for confronting the art work in a more conscious, conceptual way" (Sontag, 1981, p. 6). (Tradução nossa)
} 
íntimos do silêncio e da quietude que nós.

\section{Atos políticos}

A encenação The Acts-Vigia surgiu de uma pergunta movida por uma inquietação. Ou melhor, de uma indignação em relação a uma realidade. "Qual é o feminino de vingança? Qual é o contrário de horror?"6 A resposta em forma de espetáculo articula uma série de outras perguntas e questões, de ordem técnico-pedagógica:

qual é a prática, a preparação, para uma performance que lida com esses temas? O que uma performance pode ser, fazer ou dizer em resposta a essas realidades? [...] Eu entro em uma sala com um performer. Eu sei o que estou procurando, mas eu não posso nomeá-lo, porque eu não o vi ou ouvi. Eu não sei como se chama, mas vou reconhecê-lo quando o vir. E este é, de fato, o ponto. Eu estou procurando algo que eu ainda não vi. E eu confio em colaboradores pacientes que confiam nos meus instintos. Eu sei que não é o que o performer faz, mas a maneira como é feito: como o fazer entra em vigor. Então, eu posso começar a procurar o que eu estou procurando, trabalhando com qualquer ação ou ato oferecido. Eu trabalho para moldar o "como" das propostas oferecidas (Greenhalgh, 2006, p. 34)7.

O processo criativo de Greenhalgh geralmente tem início com uma reação pessoal relacionada a um tema ou situação ("A cada vez que começo um trabalho é porque alguma coisa me incomodou e graças à performance eu posso expressar a minha raiva") e é seguida de perguntas que vão aos poucos se transformando em imagens e pensamentos ligados à estética e à estruturação da cena (Greenhalgh, 2010, p. 139). A diretora não trabalha com um grupo fixo desde sua experiência de sete anos com o Cardiff Laboratory Theater, nos anos 1970/1980. Desde então, a sua prática dominante tem sido de articular artistas em torno de um projeto, e com frequência ela cria um modelo de relativa mobilidade, o que facilita o trânsito por diversos países, como foi o caso de The Acts. Neste exemplo, vemos uma relação clara entre o modo de produção e o modo de criação espetacular, mas não podemos estender este modelo a todo o seu trabalho.

A dificuldade de começar um novo espetáculo é reportada por ela como o desafio constante de encarar "o precipício, cada vez mais alto", que configura o início de um processo criativo. Este desafio implica também na escolha - ou não - de uma "metodologia específica", que ela prefere não assumir.

Eu não conseguia me convencer de que entrar em uma sala todos os dias, e aceitar a disciplina de treinamento, me levaria para mais perto do que eu estava procurando. Então um dia eu simplesmente parei. É tudo uma questão dos parâmetros que cada um dá a si mesmo para trabalhar, dos detectores que cada um cria para si mesmo; as suas próprias regras são esclarecidas e afinadas através do fracasso (Greenhalgh, 2006, p. 34) .

\footnotetext{
${ }^{6}$ No original: "What is the feminine of revenge? What is the opposite of terror?" (Greenhalgh, 2006, p. 34).

${ }^{7}$ No original: "what is the practice, the preparation, for a performance work addressing these issues? What can a performance be, do or say, that is of use in response to these realities? (...) I go into a room with a performer. I know what I am looking for, but I cannot name it because I have not seen or heard it. I don't know what it is called, but I will recognize it when I see it. And that, in fact, is the point. I am looking for something I have never yet seen. And I rely on patient collaborators who trust my instincts. I know it is not what the performer does, but the way that it is done: how the doing is enacted. So I can begin to search for what I am looking for, by working with any action or act offered. I work to mould the 'how' of the proposals offered". (Greenhalgh, 2006, p. 34). (Tradução nossa)

${ }^{8}$ No original: "I couldn't convince myself that going into a room every day, and accepting the discipline of training, took me any closer to what it was I was searching for. So one day I just stopped. It's all a question of the parameters one gives oneself to work within, what bullshit detectors one devises for oneself; one's own rules
} 
A diretora revela que, com o passar dos anos, adquiriu autoconfiança suficiente para entrar em uma sala no começo de um trabalho sem saber o que vai sair dali. $O$ desafio, neste caso, consiste em "descobrir novos terrenos, viajar sem instruções e sem mapa" (Greenhalgh, 2004, p. 85). Ela resume o que acontece em cada início de processo criativo como "meu processo é sobre não saber. Eu não sei, eu não sei, eu não sei..." (Greenhalgh, 2011, entrevista).

O eixo temático que deu origem a The Acts foi o feminicídio recorrente na fronteira mexicana, particularmente na cidade de Juárez. A diretora dá uma resposta pessoal e artística à tortura cometida contra jovens e adolescentes, que são estupradas e mortas nas cidades fronteiriças do norte do país, um tema que se situa entre a condição das mulheres e a violência social. Segundo ela e as fontes consultadas, apesar de haver evidências do envolvimento de chefes do tráfico local e de jovens ligados a famílias oligárquicas da região, não há provas dos crimes e a impunidade permanece. Ao tratar dessa temática em cena, Greenhalgh optou pelo silêncio. Nenhuma palavra é proferida pelas 12 performers, há uma música que se repete ad infinitum reforçada por sequências de ações e partituras gestuais muito lentas. A repetição sugere que a ação não tem fim, que o número de vítimas continua a crescer. Os espectadores são dispostos em círculo ao redor da cena e próximos a ela. A ausência e o vazio são os principais elementos da encenação. No jornal Western Mail, o crítico de arte britânico David Adams (2008) comenta:

Vigia não é um ato de vingança à violência masculina, mas uma resposta, e oferece uma forte réplica à agressão masculina e ao abuso. [...] Não há palavras neste espetáculo de uma hora, mas ele é eloquente, multi-camadas, provocador e lindamente aterrorizante. Teatro político desafiador, corajoso, deslumbrante, da melhor qualidade... ${ }^{9}$

A oposição dos adjetivos empregues pelo crítico (beautifully terrifying) revela a opção estética da diretora, que faz alusão a Sontag para explicar os recursos que utiliza na encenação: "Eu sei que tudo tem o seu oposto; que para falar do mal, tenho que falar do seu oposto - bem. Para evocar o horror devo encontrar algo extraordinariamente belo, e para trabalhar com o conceito de morte devo considerar ressurreição. Para provocar medo, eu preciso criar um lugar que é seguro."10. Ao trabalhar com este conceito, ela busca a força oposta à expectativa, quando a queda é impedida de ser completada. "E eu quero começar aqui. Este é o lugar para o qual eu sempre retorno; aqui é onde eu acho que posso revelar alguma coisa - um lampejo de sentido"11 (Greenhalgh, 2006, p. 34-35).

\footnotetext{
are what are clarified and honed through failure". (Greenhalgh, 2006, p.34). (Tradução nossa)

${ }^{9}$ No original: "What Vigia does is not an act of revenge to male violence but an answer, and offers a stark riposte to masculine aggression and abuse. [...] There are no words in this hour-long piece but it is eloquent, multi-layered, provocative and beautifully terrifying. Brave, stunning, challenging political theatre at its best..." (Adams, 2008). (Tradução nossa)

${ }^{10}$ No ensaio A Estética do Silêncio, Sontag argumenta que o "silêncio" nunca deixa de implicar os seus opostos e de exigir a sua presença. "Assim como não pode haver "para cima" sem "para baixo" ou "esquerda", sem "direita". Por isso deve-se reconhecer um ambiente envolvente de som ou de linguagem, a fim de reconhecer o silêncio. Não só o silêncio existe em um mundo cheio de discursos e outros sons, mas qualquer silêncio leva a sua identidade como uma extensão de tempo sendo perfurada pelo som." (Sontag, 1981, p. 5). No original: "I know everything has its opposite; that to speak of evil, I must speak of its opposite - good. To evoque the horror I must find something extraordinarily beautiful; and to work with the concept of death I must consider resurrection. To provoque fear I must create a place that is safe." (Greenhalgh, 2006, p. 34). (Tradução nossa)

${ }^{11}$ No original: "And I want to start here. This is the place I keep returning to; this is where I sense I may be able to reveal something - a flicker of meaning." (Greenhalgh, 2006, p. 35). (Tradução nossa)
} 
O trabalho foi apresentado em diversos países da Europa e da América Latina com elencos variados, normalmente mesclando performers locais e de outras nacionalidades. Em cada local de apresentação, a performance foi remontada (ou recriada) durante um workshop oferecido nos dias anteriores ao evento. Em Guanajuato ${ }^{12}$, México, em julho de 2011, participei da oficina, inicialmente como observadora/ assistente, e passei a integrar o elenco da performance após a saída circunstancial de uma das atrizes, quando vivi a experiência do lado de dentro. $O$ trabalho com o coletivo (jovens atrizes mexicanas que se inscreveram para participar da oficina) começou com uma conversa sobre o tema seguida de uma troca de depoimentos, quando surgiram expressões e testemunhos do tipo: "sinto impotência, frustração, paranoia, estamos doentes, sigo minha vida, estou além do nojo", etc., baseadas nas sensações e na experiência de cada participante com o tema. Em seguida, o trabalho psicofísico, em duplas ou individualmente, incluiu uma série de exercícios que buscavam desenvolver precisão, "autoridade sem agressão"13, tensão, atenção, presença. A diretora orienta: "O que prende a atenção é o que você vai fazer, não o que você está fazendo" (friso meu). Todo o trabalho é voltado para o conceito do "momento anterior a" (the moment before): a energia do momento antes da queda. Ela recorre a Hitchcock: "Não há suspense no grito, só na antecipação do grito"14 (Greenhalgh, 2006, p. 35). Vários tipos de caminhadas lentas são testados de olhos fechados e depois repetidos de olhos abertos, além de jogos que exercitam a prontidão. Ela busca nos corpos/mentes das atrizes "autoridade" na presencialidade, no aqui-agora. Um corpo pronto, ágil, perceptivo, à flor da pele. Sobre o processo de criação dessa performance, a diretora explica:

Eu estou interessada em trabalhar com a performer no momento em que o corpo está totalmente preparado para a conclusão de uma ação única, pronto para execução. O momento imediatamente antes da queda, antes do salto, antes do corte, antes do beijo, antes do sorriso, antes do adeus, antes do grito, antes do tiro, antes de a corrida começar; pronto, firme. Este é o momento que me interessa, não a ação em si. A intenção, e a clareza da intenção, é onde reside o potencial. Os espectadores estão atentos quando eles querem saber o que vai acontecer, não quando já captaram isso. [...] Ver o animal predador no momento antes de uma morte; uma leoa - seu corpo em vibração imóvel, uma quietude recolhida, tensa o momento antes da morte de sua presa, ou a sua fuga. E um momento de vida ou morte. É essa prontidão que atrai a minha atenção, o fato de que, neste momento, qualquer coisa ainda pode acontecer, não há conclusão precipitada; o desespero pode ser conquistado, a morte não é inevitável, e ela pode ser enganada. (Greenhalgh, 2006, p. 34) ${ }^{15}$.

\footnotetext{
${ }^{12} \mathrm{~A}$ performance The Acts foi recriada e apresentada pela última vez durante o Congresso Siete Caminos, realizado em colaboração com o Magdalena Project, no dia 17 de julho, no Teatro Principal, em Guanajuato, México.

${ }^{13}$ Greenhalgh trabalha frequentemente com a noção de autoridade na cena, que diz a respeito a um aprofundamento da noção de presença e se relaciona com segurança e determinação na ocupação da cena, mas sem uma autoimposição "arrogante ou agressiva" por parte do ator. A "autoridade" é trabalhada através da escolha, repetição e refinamento de gestos e ações "criveis" a partir de critérios estabelecidos pela diretora e pelo coletivo. A diretora insiste na ideia de ocupar a cena com autoridade enquanto mulher.

${ }^{14}$ No original: "There is no suspense in a scream, only in the anticipation of a scream." (Greenhalgh, 2006, p. 35). (Tradução nossa)

${ }^{15}$ No original: "I am interested in working with the performer in the moment when the body has fully prepared its whole self for the completion of one unique action, in readiness for execution. The moment just before the fall, just before the jump, just before the cut, just before the kiss, just before the smile, just before goodbye, just before the scream, just before the shot, just before the race begins; ready, steady. This is the moment that interests me, not the action itself. The intention, and the clarity of the intention, is where potential lies. The spectators are held when they want to know what will happen next; they are not held when they have already sussed it. [...] Watch the predatory animal in the moment before a kill; a lioness - her body in motionless vibrancy, a gathered, taut stillness - the moment before the death of her prey, or its escape. It is a life or death moment. Is it this readiness that attracts my attention, the fact that at this moment anything can still happen; there is no foregone conclusion; despair can be conquered, death is not inevitable, and can be cheated" (Greenhalgh, 2006, p. 34). (Tradução nossa)
} 
O "momento anterior" a que se refere Greenhalgh pode ser entendido como um espaço intersticial: entre ausência e presença, entre passivo e ativo, entre realidade e ficção, entre vida e morte. Entre o corpo que se equilibra precariamente e a queda. $O$ que acontece nesse exato momento que mobiliza o todo psicofísico da performer? É essa qualidade que é preciso manter viva para cativar o espectador. Como no sats ${ }^{16}$ de Barba, que provoca o corpo a reagir com tensões inclusive na imobilidade, dado que ele é "impulso e contra-impulso", é suspensão da ação, é "a mola antes de saltar" que dilata as dinâmicas do corpo (Barba, 1994, p. 84-87), o "momento anterior" proposto por Greenhalgh visa comprometer o corpo inteiro, mantendo pensamento e ação ligados entre si.

Em The Acts, o desenho do espetáculo é claro, a performance já foi realizada diversas vezes ${ }^{17}$ e não há muito espaço para alterações ou contribuições de maior porte, apesar da mudança de elenco. As atrizes funcionam como actantes ${ }^{18}$, identidades em movimento, não há qualquer alusão a personagens fixas ou abordagem emocional na criação. A atriz não é "alguém que representa um papel, mas um performer que oferece à contemplação sua presença no palco". Sua "'não-atuação' se refere a uma presença na qual o ator não faz nada para reforçar a informação transmitida por sua atividade". É possível aplicar aqui a situação de "atuação sem matriz" proposta por Lehmann, na qual a atriz não está vinculada à matriz de um contexto de representação (Lehmann, 2007, p. 225). Greenhalgh explora uma gestualidade lenta e precisa, propõe percursos que traçam diagonais no espaço, faz contagens que definem o ritmo da cena. Pede às atrizes que encarem pessoas específicas na plateia com "um olhar não agressivo, presente, destemido". Insiste para que não expressem, apenas estejam (grifo meu). Impõe um silêncio quase meditativo. Em um dos exercícios feitos em dupla, as atrizes despem uma à outra em um ritmo extremamente lento e voltam a se vestir. Depois, na cena, esta ação é repetida diversas vezes, em duplas ou individualmente, quando cada uma das performers despe ou veste uma calcinha branca de algodão, num total de cinco, que vão sendo largadas, formando um desenho macabro e ao mesmo tempo poético no chão, uma trilha de peças íntimas dispersas pelo espaço. O palco do teatro está todo aberto, urdimento e coxias visíveis com pequenos focos de luz pendurados sobre a cena. O público está sentado em cadeiras formando um grande círculo sobre o palco e ao redor da cena. No meio do círculo, deitada em um colchão, uma atriz espeta pregos ao redor do próprio corpo, criando uma silhueta que remete ao corpo das vítimas assassinadas, ao mesmo tempo em que o ritual lembra a prática de vodu. $O$ ambiente é quase solene, pode-se ouvir cada respiro. As atrizes se aproximam alternadamente de pessoas no público e olham fixamente nos olhos do espectador enquanto se despem. As roupas cotidianas

\footnotetext{
${ }^{16} \mathrm{O}$ termo sats é definido por Barba como "o momento no qual a ação é pensada-executada por todo o organismo que reage com tensões também na imobilidade. É o ponto no qual se está decidido a fazer. Existe um empenho muscular, nervoso e mental já dirigido a um objetivo. É a extensão ou retração da qual brota a ação." (Barba, 1994, p. 84).

${ }^{17}$ Ressalto aqui uma contradição entre o sentido formal dado à palavra performance e o sentido em que ela é usada nesse contexto, entendendo que uma das características do ato performativo é a sua não-repetição.

${ }^{18}$ Matteo Bonfito se refere ao termo actante como "tudo aquilo que atua" (Teixeira Coelho apud Bonfitto, 2002) ou "aquele que executa ou sofre o ato" (Greimas apud Bonfitto, 2002).
} 
das performers e seus gestos delicados, lentos e cuidadosos no ato de despir e vestir a outra se contrapõem ao abuso e à agressão perpetrada contra seus corpos no caso real de Juárez. A atuação é um misto de ações que contêm vulnerabilidade e força.

Em The Threat of Silence, Greenhalgh faz uma imersão mais intensa no silêncio e propõe ao espectador uma experiência de escuta, evocando os diversos elementos do teatro - espaço, texto, ação, imagem, som - para provocar uma "desaceleração" no público. Mais do que nos abordar com movimentos, sons e palavras, a diretora propõe a perspectiva de uma escuta atenta, que ouve através e além do que é dito e mostrado a partir do mergulho no silêncio. O trabalho apresenta imagens projetadas sobre uma grande tela que ocupa o fundo do palco, intercalando imagens de paisagens duplicadas em efeito espelho com imagens de pessoas e textos. Na cena, uma musicista toca cello e uma atriz/cantora/performer/dançarina canta canções em inglês e em galês e atua sequências de movimentos e ações, alternada ou simultaneamente. As imagens mostradas na tela por vezes se confundem com o gestual estilizado da performer Eddie Ladd. Outras vezes provocam estranhamento e rupturas entre as diversas partes da cena. Novamente, recorremos a Sontag para pensar sobre o percurso criativo da diretora.

Para perceber a plenitude, devemos manter um sentido agudo do vazio que o marca, inversamente, a fim de perceber o vazio, devemos apreender outras zonas do mundo como cheias. [...] Um verdadeiro vazio, um silêncio puro, não são factíveis - tanto conceitualmente ou de fato. Se apenas porque a obra de arte existe em um mundo equipado com muitas outras coisas, o artista que cria silêncio ou vazio deve produzir algo dialético: um vazio completo, um vazio enriquecedor, um silêncio ressonante ou eloquente. $\mathrm{O}$ silêncio continua a ser, inevitavelmente, uma forma de discurso (em muitos casos, de queixa ou acusação) e um elemento em um diálogo (Sontag, 1981, p. 5) ${ }^{19}$.

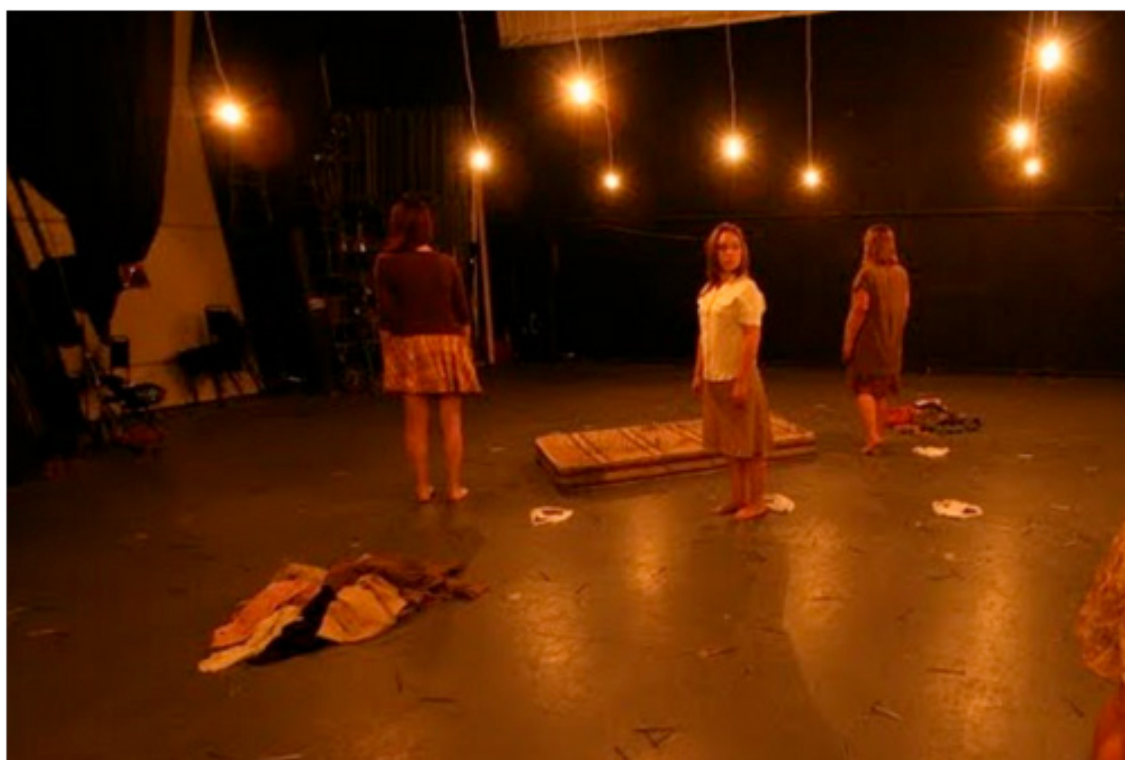

Figura1 - The Acts - Vigia - Foto: Pia Siliceo

\footnotetext{
${ }^{19}$ No original: "In order to perceive fullness, one must retain an acute sense of the emptiness which marks it off; conversely, in order to perceive emptiness, one must apprehend other zones of the world as full. [...] A genuine emptiness, a pure silence, are not feasible - either conceptually or in fact. If only because the art-work exists in a world furnished with many other things, the artist who creates silence or emptiness must produce something dialectical: a full void, an enriching emptiness, a resonating or eloquent silence. Silence remains, inescapably, a form of speech (in many instances, of complaint or indictment) and an element in a dialogue." (Sontag, 1981, p.5). (Tradução nossa)
} 


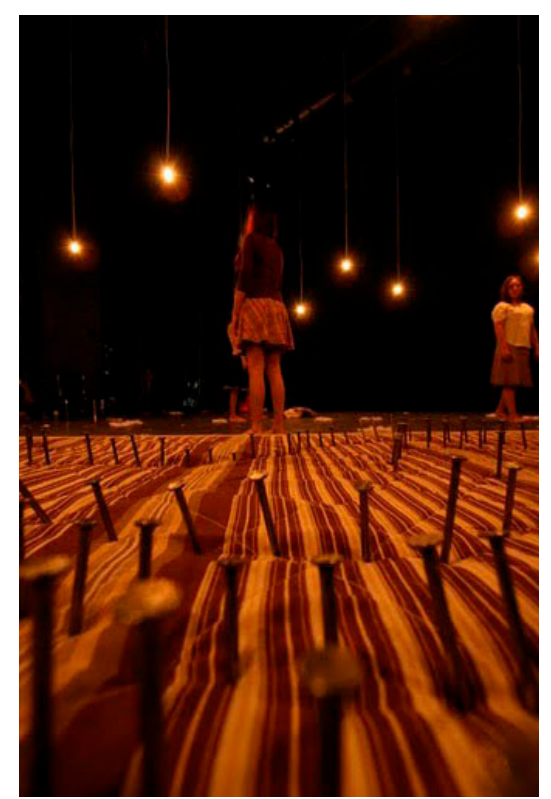

Figura 2 - The Acts - Vigia - Foto: Pia Siliceo

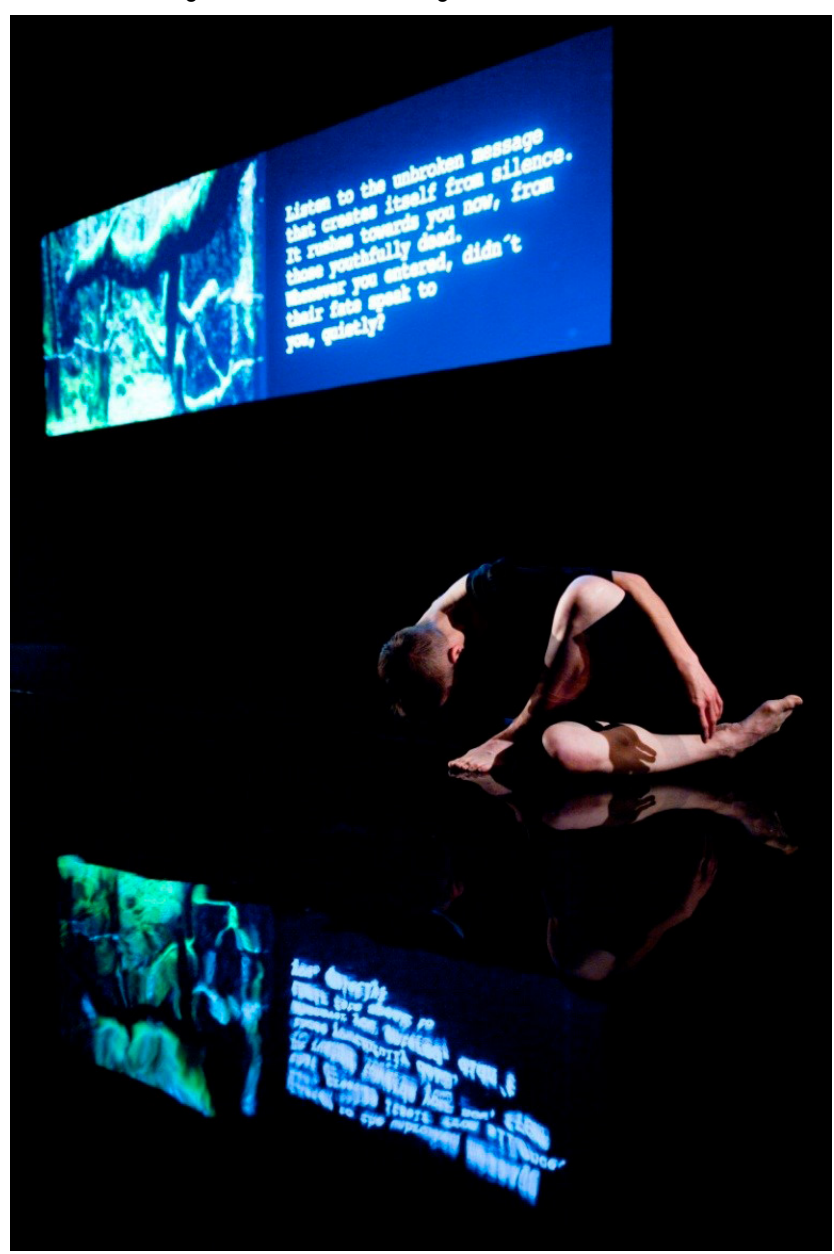

Figura 3 - The Threat of Silence - Foto: Keith Morris 


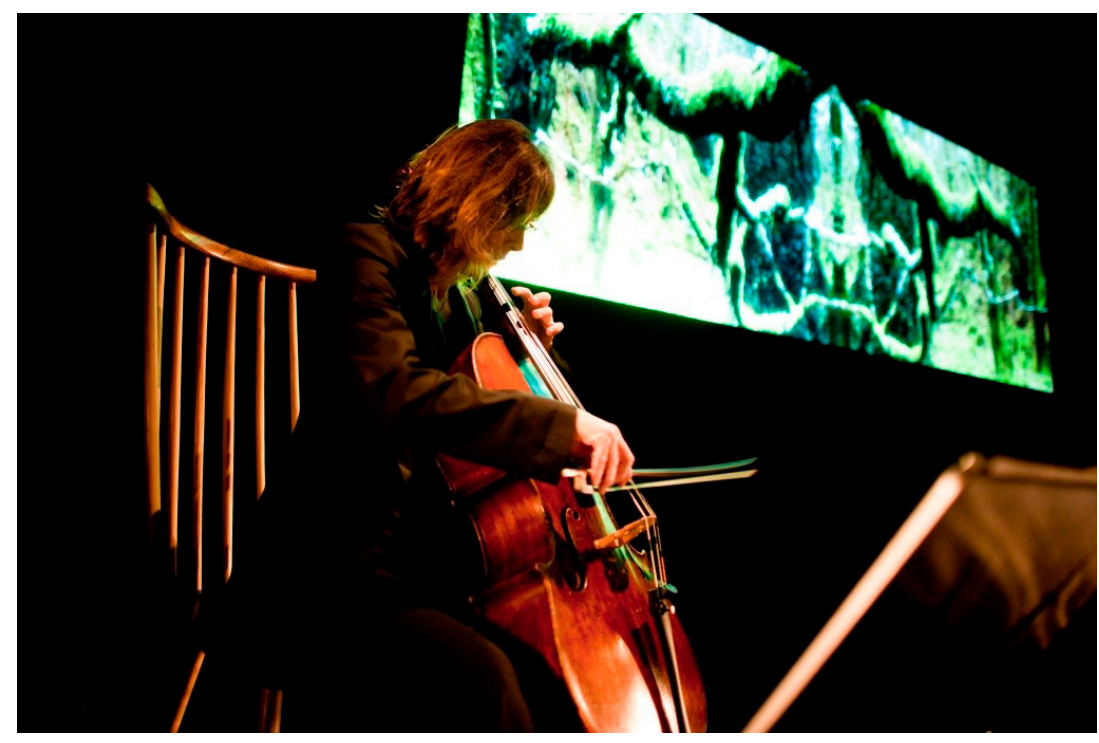

Figura 4 - The Threat of Silence - Foto: Keith Morris

No programa, Greenhalgh afirma que não sabe como chamar a obra: performance, concerto, cerimônia, oração, súplica, um chamado, talvez tudo isso? O trabalho foi criado de forma colaborativa com artistas renomadas de diferentes áreas: uma videasta norueguesa, uma escritora australiana, uma performer e uma musicista, ambas galesas. A criação e produção do trabalho seguiu um formato colaborativo, no qual encontramos uma interferência autoral forte por parte dos diversos profissionais envolvidos na montagem, implicando em uma desierarquização das funções, cujas relações flutuam continuamente entre subordinação e coordenação (Silva, 2008).

Em entrevista concedida em 1990, portanto vinte anos antes da montagem em questão, Greenhalgh fala sobre a recorrente primazia da hierarquia do texto/autor, seguida da direção, sobre os demais elementos espetaculares que marca a história do teatro e se refere ao seu olhar e à sua própria experiência com devised theatre como uma tentativa de horizontalização nas relações. Ela se refere a cada elemento como unidades distintas (ator, diretor, texto, cenógrafo, músico) que, juntas, atuam de forma interdependente em um processo de criação horizontal que é guiado pelo que o ator e seus materiais têm a oferecer ao diretor.

Eu não estou usando palavras dos dramaturgos e as interpretando... Eles [os atores] vêm com seu próprio material, ideias ou improvisação física ou material fixado que eles cedem ao diretor. Então, o diretor tem uma quantidade de materiais que lhe foram concedidos e começa a colar e construir e manipular... o material que lhe foi dado. Ao invés de dizer: "esta é a peça que nós vamos montar, esta é a parte que você vai atuar - interprete" (Greenhalgh, 1990, p. 4) ${ }^{20}$.

No processo de construção de The Threat of Silence, ela escolheu trabalhar com artistas maduras, cujo trabalho está sedimentado. $O$ ponto de partida foi perguntar a cada uma delas o que significa quietude na música, no filme, na escrita.

\footnotetext{
${ }^{20}$ No original: "I'm not using playwrights words and interpreting them... They are coming with their own material, albeit ideas or physical improvisation or fixed material that they give to a director. The director then has a 'pot' of material that has been given to him/her, and begins to collage and construct and manipulate... the material they have been given. Rather than saying, "this is the play we are doing, this is the part you are going to play - interpret it." (Greenhalgh, 1990, p. 4). (Tradução nossa)
} 
"É maravilhoso falar sobre silêncio com uma escritora. Ou com uma musicista. Elas entenderam. Nós estávamos todas procurando a mesma coisa"21 (Greenhalgh, 2011, entrevista). O trabalho resultou em um espetáculo que não trata de um tema político, mas faz uma abordagem mais "filosófica, espiritual". Ela se diz interessada em criar um espaço de reflexão - não em contar coisas, não em preencher com coisas que a plateia tem que seguir - mas em criar um espaço para as pessoas pensarem no que é importante para elas. "Nós perdemos no ocidente os espaços de reflexão. Será que o teatro, como um espaço vivo entre pessoas, pode se tornar um espaço de reflexão? É nisso que estou interessada" (Greenhalgh, 2012, depoimento pessoal durante o processo de Dohter). A escolha por uma estética performativa, que se distancia da visão mais clássica e do sentido mimético do teatro, a permite explorar possibilidades de envolver o espectador no jogo. Como afirma Féral, "a performance não precisa dizer (como no teatro), mas provocar relações sinestésicas de sujeito a sujeito" (Féral apud Silva, 2008, p. 256). Sobre este aspecto, Sontag reflete:

O silêncio é uma metáfora para uma visão limpa, sem interferência, em que se poderia prever a feitura de obras de arte que não respondem antes de ser vistas, que são invioláveis em sua integridade essencial pelo escrutínio humano. O espectador abordaria a arte como ele aborda uma paisagem. Uma paisagem não exige do espectador a sua "compreensão", suas imputações de significado, suas ansiedades e simpatias; exige, antes, a sua ausência, que ele não acrescente nada. Contemplação, estritamente falando, implica auto-esquecimento por parte do espectador: um objeto digno de contemplação é o que, de fato, aniquila o sujeito que percebe ${ }^{22}$ (Sontag, 1981, p. 7).

Na oficina A Ameaça do Silêncio, ministrada por Greenhalgh em Florianópolis, durante o Vértice Brasil 2012, a diretora propôs diversas práticas que podemos chamar de meditativas, visando trabalhar as dificuldades do "estar presente". Grosso modo, a meditação consiste em uma prática/disciplina que trabalha sobre os polos da contemplação e da concentração, com o objetivo de "desligar-se" do mundo exterior e voltar a atenção para dentro de si. Em uma de suas dimensões mais correntes, e com maior aplicação no campo do teatro, a meditação propõe um "esvaziamento da mente" através da tentativa recorrente, e jamais cumprida, de limpar os pensamentos e de permanecer conectado com o aqui-e-agora.

Greenhalgh propôs uma sequência de exercícios que demandavam alguns (poucos ou muitos) minutos de silêncio, em duplas, sozinho ou no grande grupo, a partir de algumas prerrogativas dadas por ela. $O$ feedback dado pelas participantes se aproximou das reflexões de Irigaray sobre o silêncio como um lugar propício ao encontro entre o eu e o outro, apesar das diferenças.

O silêncio é a primeira palavra dirigida ao outro. É o sinal da minha disponibilidade em aceitá-lo/a como é, sem dobrá-lo/a ao meu discurso, sem incluí-lo/a no

\footnotetext{
${ }^{21}$ No original: "It is wonderful to speak to a writer about silence. Or to a musician about silence. They understood. We were all looking for the same thing" (Greenhalgh, 2011, entrevista). (Tradução nossa)

${ }^{22}$ No original: "Silence is a metaphor for a cleansed, noninterfering vision, in which one might envisage the making of art-works that are unresponsive before being seen, that are inviolable in their essential integrity by human scrutiny. The spectator would approach art as he does a landscape. A landscape doesn't demand from the spectator his "understanding," his imputations of significance, his anxieties and sympathies; it demands, rather, his absence, that he not add anything to it. Contemplation, strictly speaking, entails self-forgetfulness on the part of the spectator: an object worthy of contemplation is one which, in effect, annihilates the perceiving subject." (Sontag, 1981, p. 7). (Tradução nossa)
} 
meu mundo. Manter o silêncio diante do outro é uma forma de reconhecer o outro como outro, de mostrar-lhe a minha capacidade de respeitá-lo por aquilo que ele é, sem impor os meus padrões ou os meus hábitos (Irigaray, 2011, p. 79) ${ }^{23}$.

O silêncio aqui é tratado como atitude de escuta do outro, como forma de admitir a verdade alheia que não necessariamente coincide com a minha e que, portanto, não deve ser submetida à minha própria razão. Em The Threat of Silence, o silêncio não é imposto como ameaça, mas como um convite ao desconhecido.

\section{Testemunho pessoal}

Em Dohter, observamos um modo de produção semelhante ao de The Acts, com a reunião de núcleos de criação dentro de um evento (festival/encontro ligado à rede) que geram uma performance autônoma como resultado de um período curto e intensivo de trabalho. Dohter é uma palavra em inglês arcaico que significa Daughter, filha. A diretora tem duas filhas que haviam deixado recentemente a casa da família para seguir seus estudos na universidade. O período de transição entre a longa preparação para a partida das filhas e a partida em si serviu de ignição para uma reflexão sobre os relacionamentos entre mães e filhas. Sobre o que é ser filha. Sobre o que é ter filha. A partir deste tema, surgiram questões que foram trabalhadas pela primeira vez em um formato intensivo com 12 performers de nacionalidades distintas, em Cardiff, em agosto de $2011^{24}$. Os materiais gerados neste processo e os procedimentos criativos experimentados teriam como propósito servir de estímulo para a elaboração de um conceito e a invenção de uma forma para o projeto Dohter, que no ano seguinte teve continuidade no Brasil.

No primeiro encontro, ao som de um cello tocado por uma das artistas, a diretora fala em um necessário "esvaziamento" antes de começar o trabalho. O esvaziamento (emptiness) é um conceito-chave da filosofia budista. A palavra Sunyata (em sânscrito) diz respeito a um esvaziamento da mente, interdependência, evocando uma atitude de desprendimento e abertura. Percebe-se uma preocupação da diretora em criar um ambiente de trabalho que inspire confiança e gere "inteireza" nas participantes, um ambiente denso sem ser tenso, particularmente porque certamente surgiriam depoimentos íntimos e de forte carga emocional. Ela define a organização de cada encontro, que fica dividido em três grandes momentos, que por sua vez são subdivididos em etapas específicas:

1) aquecimento / trabalho físico e vocal;

\footnotetext{
${ }^{23}$ No original: "Il silenzio è la prima parola rivolta all'altro. Ė il segno della mia disponibilità ad accoglierlo(a) così com'è, senza piegarlo(a) al mio discorso, senza includerlo(a) nel mio mondo. Mantenere il silenzio di fronte all'altro è un modo di riconoscerlo in quanto altro, di manifestargli la mia capacità di rispettarlo per quello che è, senza imporgli le mie norme o le mie abitudini." (Irigaray, 2011, p. 79). (Tradução nossa)

${ }^{24}$ Originalmente Jill Greenhalgh convidou cinco artistas para trabalhar com ela durante uma semana, após a realização do evento Legacy and Challenge, comemorativo dos 25 anos do Projeto Magdalena, em Cardiff, no País de Gales. Eram elas: Brigitte Cirla (França), Eddie Ladd (Gales), Gabriella Sacco (Itália), Meg Brookes (Gales) e Roxana Piñeda (Cuba). No decorrer do evento, ela convidou outras artistas para integrar o grupo, que passou a contar com a colaboração de Aylin Lobeck de Fabris (Germany), Dawn Albinger (Australia), Eugenia Cano Puga (México), Katt Osborne (Australia), Kordula Lobeck de Fabris (Germany), Vanessa Gilbert (USA) e eu (Brasil). O grupo tinha uma formação bastante heterogêna, tanto em relação ao seu background teatral quanto em relação ao país de origem e à faixa etária, que ia de 17 a 60 anos. No meu caso específico, minha presença estava prevista desde o início como observadora, mas tive participação ativa em alguns momentos (na cena ou propondo exercícios) e participei da apresentação final.
} 
2) criação de material;

3) improvisação e trabalho de composição.

Em seguida, ela lança duas perguntas que são respondidas por todas e compartilhadas no círculo. As perguntas são: "Que filha eu sou?" e "Que filha eu quero/não quero?". Ao final da conversa, ela diz que, para ela, em cada trabalho "tem que haver algo que me toca realmente fundo".

No trabalho cotidiano, exercícios de diferentes fontes são propostos para a geração de materiais: exercícios que trabalham com presença e pausa, com variações de ritmo e tensão, coletivos e individuais, com frequência envolvendo música (ao vivo) e/ou canto ${ }^{25}$ (conduzidos por Greenhalgh) e uma sessão de Movimento Autêntico ${ }^{26}$ (conduzida por mim). Durante a etapa de improvisação e composição, cito algumas das práticas adotadas: square dance (dança dos quadrados - exercício com raias que se cruzam formando um ou vários quadrados, nos quais as performers circulam e seguem determinadas regras - como falar uma frase ou criar uma imagem, por exemplo - a cada vez que se encontram, conduzido por Greenhalgh); breath orchestra (orquestra de sopro ou respiração - um coro, conduzido por Brigitte Cirla, que mistura frases, ritmos respiratórios e imagens - como gotas de água, sons de pássaros e trovões - obedecendo a determinadas regras relativas às vozes, intensidades, dinâmicas, crescendo e decrescendo com o objetivo de estimular a criação de sons "instáveis" e desconhecidos); práticas envolvendo canto e texto; pesquisas de movimento relacionadas às forças de atração e repulsão presentes nas moléculas e átomos, além de improvisações dirigidas sobre materiais criados individualmente. Cito ainda algumas observações feitas pela diretora durante o processo compositivo, que ajudam a compreender o tipo de pensamento que a guia:

"Seja mais e pense menos";

"Não faça a história, ESTEJA na história";

"Não importa qual seja a proposta, nós temos que saber o que fazer com ela. Não ignorar";

"Não perca os momentos de proposições";

"Eu procuro por calma onde 'nada' acontece. Tem coisas demais acontecendo. O que é que vem agora?";

"Como recriar as condições para que a improvisação funcione?";

"Como fazer menos sem reduzir a criação?"

"Quais são os princípios que estão sendo empregues quando alguma coisa funciona?"27.

\footnotetext{
${ }^{25} \mathrm{O}$ grupo "original" (as cinco artistas convidadas originalmente) tem forte relação com a música e o canto, sendo que duas delas são musicistas.

${ }^{26}$ Movimento Autêntico é uma prática de movimento, criada pela americana Mary Starks Whitehouse nos anos 50 , fortemente influenciada pela sua formação como bailarina moderna (estudou na Escola Mary Wigman, na Alemanha) e sua experiência em análise junguiana, que lhe despertou o interesse pelo simbolismo e pela expressão de conteúdos na ação física humana. Sua principal característica consiste em ser uma experiência de movimento de olhos fechados baseada na relação entre quem se move e quem testemunha (mover e witness), favorecendo a emergência de uma consciência e percepção de si e do outro, possibilitando também o desenvolvimento de uma "testemunha interna". Sua utilização no processo criativo de Dohter consistiu em uma sessão múltipla, com várias movedoras e testemunhas. Após vinte minutos de movimento, cada testemunha deu feedback ao seu par e "selecionou" quatro fragmentos de movimento, que foram repetidos, refinados, registrados e transformados em uma sequência de ações, que passou a integrar os materiais de cada performer.

${ }^{27}$ No original: "Be more and think less"; "Don't make the story, BE in the story"; "Whatever the proposal is, we have to know what to do with it. Not ignore"; "Don't lose the moments of propositions"; "I look for stillness where 'nothing' happens. There is a lot going on. What's coming next?". (Tradução nossa)
} 
Greenhalgh insiste em buscar momentos em que força e vulnerabilidade surjam simultaneamente na atuação. Ela reforça que quer "coisas reais, ações reais": enquanto tenta eliminar qualquer tentativa ou resquício de over-acting ou de showing-off 28 O silêncio continua sendo uma presença constante, marcado, fundamentalmente, por um tipo de atitude na cena, mais do que por pausas ou desaceleração, também evidentes. $O$ resultado do trabalho desenvolvido durante a semana - uma colagem de oito fragmentos de cenas, costuradas através de textos escritos e música - foi apresentado para um grupo restrito de pessoas como um work in progress que tinha como objetivo, como já foi exposto anteriormente, levantar possibilidades conceituais e cênicas que pudessem ser desenvolvidas no decorrer do projeto.

A segunda etapa (ou talvez a primeira "versão oficial") de Dohter aconteceu em Florianópolis, durante o encontro/festival Vértice Brasil, em junho/julho de 2012. 0 processo se configurou como uma espécie de residência artística oferecida pela diretora para 10 artistas locais ${ }^{29}$ durante duas semanas anteriores ao festival, onde o work in progress ${ }^{30}$ com duração de 25 minutos foi apresentado na abertura do evento. Desta vez, o trabalho teve um rumo diferente. Alguns dias antes de começar o processo, Greenhalgh pediu às participantes que escolhessem uma parceira externa com quem trabalhar. Por e-mail, ela explicou:

\begin{abstract}
Estou interessada em explorar, com mulheres de diversas partes, histórias pessoais que emerjam das experiências e reflexões relacionadas com ser filha ou ter filha(s). Cada participante precisa pensar cuidadosamente, escolher e convidar uma parceira com quem gostaria de trabalhar em colaboração por pelo menos uma hora ao dia durante o workshop. Esta pessoa não estará presente no workshop. Esta parceira deveria ser, idealmente, mas não necessariamente, alguém próximo - a mãe ou uma filha. Se não for a mãe ou a filha, então alguém em quem a participante confie e de quem goste e que, portanto, terá vontade de compartilhar e explorar as suas histórias e biografias com a participante do workshop à medida que ela desenvolver material que brote deste diálogo (uma avó ou tia, por exemplo, ou uma vizinha mais velha) (Greenhalgh, 2012).
\end{abstract}

Ela também solicitou que cada integrante do projeto reunisse documentos (como cartas, certidões, fotografias), ressaltando que fossem reais e que provocassem alguma ressonância pessoal. Ela solicitou ainda objetos (herdados ou que contivessem alguma memória ou significado importante) e textos. Cada atriz deu início a um caderno de notas, com trechos de histórias, memórias e imagens, antes de começar o processo criativo.

No primeiro dia com o grupo, ela esclareceu que não trabalha com nenhum método ou forma específicos ("eu me reinvento a cada projeto") e que o grupo partiria dos primeiros materiais coletados para inventar uma forma. O seu modo

\footnotetext{
${ }^{28}$ Termos que se referem a uma interpretação exagerada ou afetação. Na verdade, a diretora não lida com a perspectiva de interpretação

${ }^{29}$ As artistas foram convidadas pela organização do festival, tendo como critérios a disponibilidade de imersão no processo e a variedade de bagagens, habilidades e faixa etária. 0 grupo foi composto por atrizes e bailarinas de formações e práticas bem distintas com idade de 19 a 67 anos e uma videomaker.

${ }^{30} \mathrm{O}$ termo work in progress aparece com frequência como sinônimo de work in process. No conceito está embutida a noção de "obra em feitura, de risco, de projeção ao longo do tempo/espaço". Ela carrega tanto a noção de trabalho quanto a de processo: trabalho enquanto obra acabada, resultado, mas também percurso, obra em feitura. Processo como iteratividade, permeação, risco ligado ao fato de o processo não se fechar enquanto produto final (Cohen, 1998, p. 20-21). No caso de Dohter, a ideia de obra inacabada, em andamento, é fundamental, seja porque a performance é parte integrante de um projeto de maior porte, que comporta outros estágios e momentos, permanecendo, portanto, em processo, seja porque a sua apresentação funcionou como um corte no seu processo de criação.
} 
de apresentar o formato que o trabalho teria já é uma indicação bastante forte de como o seu modus operandi está fundamentado em um trabalho colaborativo ${ }^{31}$ (devised theatre) ou uma aproximação a ele, no sentido de não trazer um texto pré-estabelecido e criá-lo conjuntamente (mesmo que ela tenha exercido a função final de dramaturga, dando a última palavra sobre o que iria pra cena), em delegar uma função autoral aos intérpretes-criadores, em trabalhar em colaboração com todos os integrantes da cena, inclusive a videomaker, mantendo as atribuições específicas de cada função, mas trabalhando de forma fundamentalmente dialógica ${ }^{32}$. Também é interessante observar que, apesar da negação do uso de uma metodologia específica, pode-se perceber a existência de um modo de operar recorrente em sua prática, levando-nos a refletir sobre as diferenças entre modo e método levantadas por Silva, que propõe a problematização deste binômio ${ }^{33}$ (Silva, 2008).

A prática foi dividida em três principais momentos, como na experiência em Gales, e a atenção da diretora foi direcionada para trabalhar o que ela chama de "autoridade" na cena. Um exercício específico, apelidado de Annie's game (jogo da Annie), foi o principal gatilho articulador da "presentificação" na cena. O jogo consistia em a performer ${ }^{34}$ entrar no espaço vazio, encontrar um lugar na sala, se apresentar e completar a frase "o que realmente importa pra mim é...". Do outro lado da cena, as espectadoras observavam atentamente e procuravam perceber o que sentiam psicofisicamente (no próprio corpo) ${ }^{35}$ a cada movimento/ação da performer em cena. Depois, o grupo discutia o que funcionava, o que não funcionava e por quê. As indicações da diretora eram: "É preciso achar o que está no meio - entre o ator e o espectador"; "é importante levar para o palco o que é importante para nós"; "preenchendo o espaço com o que é importante para mim, o outro pode escutar"; "o que importa não é o que você faz, mas como o faz" (grifos meus). A partir deste jogo, toda a ética e também a poética que regeriam a encenação estavam dadas: a importância da escuta, o jogo com a alteridade, a confiança em si mesma, o respeito à estrutura e às regras estabelecidas, a decisão e o controle sobre o olhar, a precisão nas ações, a simplicidade, a ocupação do espaço com autoridade.

A partir de uma experiência de Movimento Autêntico ${ }^{36}$ conduzida por mim, cada performer criou ações que foram partiturizadas e passaram a constituir o principal material de cada uma, a partir do qual surgiram derivações, na relação com objetos,

\footnotetext{
${ }^{31} \mathrm{Na}$ língua inglesa há dois termos comumente empregues para descrever este tipo de experiência: collaborative work, mais utilizado nos EUA, e devised theatre ou devised performance, mais utilizado no Reino Unido e Austrália. De acordo com Heddon e Milling, o termo devised performance normalmente está ligado a uma estrutura de criação não-hierárquica, de características colaborativas, ao uso de linguagem experimental não-literária, à negação de certas convenções teatrais, entre outros. No livro Devising Performance: a critical history, as autoras se dedicam a analisar a prática de devising no decorrer dos anos e em diferentes companhias, visando inclusive minimizar o status quase mítico que o termo adquiriu na segunda metade do século XX. É interessante observar que este tipo de prática costuma ser ensinado nas universidades, nos cursos de teatro e performance, como disciplina curricular. Ver Heddon, Deirdre; Milling, Jane. Devising performance. A critical history. New York: Palgrave Macmillan, 2006.

${ }^{32}$ A videomaker relata que, em uma divergência de opiniões durante a edição de imagens, ouviu de Greenhalgh: "isto aqui é arte, não é democracia", o que atesta a primazia de sua opinião final sobre a obra, mas não diminui a validade de todo o processo colaborativo que se realizou efetivamente.

${ }^{33}$ Em sua tese de doutorado, Antônio Araújo Silva atenta para as semelhanças metodológicas existentes entre "criação coletiva" e "processo colaborativo" (fazer coletivizado e diretriz dialógica, entre outros), mas ressalta as sutis, ou nem tanto, diferenças relativas ao modo como se opera a inter-relação entre os diferentes elementos da criação (Araújo, 2008).

${ }^{34} \mathrm{O}$ grupo era constituído tanto por atrizes quanto por bailarinas e como a diretora designava a todas como performers, adotei o termo performer de maneira genérica.

${ }^{35}$ É interessante ressaltar que, durante a observação das participantes do "jogo" (Annie's game), a diretora insistiu que cada observadora/testemunha observasse o que acontecia em seu próprio corpo, evitando que a análise do material fosse meramente intelectual. 0 corpo e as reações somáticas serviam de referência para uma observação "mais orgânica", que levava em consideração uma auto-observação minuciosa do ponto de vista da recepção.

${ }^{36}$ Volto a chamar a atenção para o fato de que a experiência de Movimento Autêntico, voltada para o relacionamento entre "movedor" e "testemunha", propicia uma ponte cognitiva entre o eu e o outro, diminuindo a distância entre sujeito e objeto, observador e observado.
} 
com o figurino, com o cenário, com o texto e com as demais. $O$ texto foi criado individualmente a partir de fragmentos selecionados das conversas com as "parceiras ausentes" e refinado cotidianamente de acordo com as indicações da direção e com as sugestões do grupo e transformado em material dramatúrgico. Os textos obedeciam a uma estrutura particular formada pelo binômio eu disse/ela disse, que introduzia cada fala proferida na cena, reforçando a presença/ausência do/a outro/a. Também foram coletados imagens e sons que foram editados e passaram a integrar a cena. Uma das questões que norteou o trabalho foi "como tornar a ausência uma presença constante" (novamente em referência às parceiras ausentes, mas não apenas) e a resposta veio em forma de vários materiais criados a partir desta relação, tornando-a evidente na encenação.

Greenhalgh buscou produzir uma qualidade de presença na cena como algo que se contrapõe à necessidade de criação de sentidos. Hans Gumbrecht, em Produção de presença, se refere a um tipo de relação a ser construída entre espectador e obra que ele identifica como efeito de presença, que é marcada por uma relação corporal intensa com o interlocutor. Segundo ele, "a tensão/oscilação entre efeitos de presença e efeitos de sentido dota o objeto de experiência estética de um componente provocador de instabilidade e desassossego" (Gumbrecht, 2010, p. 137). Em Dohter isso se deu através de uma tessitura dramatúrgica que envolveu o entrelaçamento de depoimentos pessoais e construção fictícia, sensações e afetos, e trabalhou com um fio muito tênue de demarcação entre arte e vida, reforçados no treinamento da atriz/performer, que foi pautado pelas tensões entre autoridade e vulnerabilidade. Apesar de a experiência individual ter constituído a base dramatúrgica, o que emergiu foi uma cena que ultrapassava em muito esta dimensão. O que observamos foi a emergência de uma tensão que Bonfitto localiza entre o pessoal e o impessoal na atuação, que exige do performer um envolvimento completo e, ao mesmo tempo, um distanciamento no modo de atuar (Bonfitto, 2009, p. 182-183). Várias indicações dadas às performers provocavam pequenos deslocamentos e rupturas que impediam uma identificação total, gerando efeitos de distanciamento em diversos níveis e agindo sobre a ideia de corpo vivo e atento ao entorno.

O trabalho que foi apresentado como work in progress consistiu em uma instalação composta de nove nichos cenográficos, que foram batizados de "altares", onde estavam expostos alguns dos objetos, documentos, móveis e fotografias selecionados no decorrer das duas semanas de trabalho, e de uma tela onde era projetado um vídeo produzido com imagens e sons das "parceiras ausentes". Cada performer tinha uma partitura de ações que se repetia no tempo, intercalada por pausas de duração variável, e todas estavam em cena simultaneamente, possibilitando ao espectador circular entre os "altares", detendo-se em um eventualmente, ou escolher por acompanhar integralmente duas ou três "vozes" que compunham este coral polifônico. Apesar de o vídeo ter uma narrativa com início e fim, as cenas ao vivo compunham uma espécie de construção in continuum, que poderia sem interrompida ou iniciada a qualquer momento sem prejuízo. Nesta experiência de Dohter, o jogo com a alteridade se apresenta fortemente: 1) na relação de negociação permanente com a "parceira ausente", que se deu durante todo o processo e se evidenciou na poética da cena; 2) no jogo de tensões estabelecido entre autonomia e pertencimento à coleti- 
vidade entre as diversas performers na cena, que atuavam simultaneamente e necessitavam de uma forte dose de escuta e alto grau de sensibilidade para que a proposta de intimidade fosse resguardada e a relação com o silêncio pudesse permanecer; 3 ) com o/a espectador/a, que ocupa um espaço bastante próximo das atrizes, compartilhando de forma quase íntima a sua atuação; 4) na experiência de escuta provocada pelo desenho e ambientação da cena, marcada por pausas e repetições.

É evidente no trabalho de Greenhalgh a motivação política presente em suas escolhas temáticas e sua concepção estética. Um dos motores propulsores de sua criação é efetivamente a indignação, a necessidade de "fazer algo" a partir de uma realidade dada. Por outro lado, também é evidente como a diretora se apropria de sua experiência subjetiva e a compartilha com as atrizes, provocando testemunhos e uma resposta/ação com ressonância pessoal em cada uma das integrantes do trabalho, o que gera uma tensão constante entre mundo e casa, público e privado.

No processo criativo e nos modos de atuação presentes nos três espetáculos analisados, encontramos uma criação de estados de vulnerabilidade que, ao gerarem incerteza e indeterminação, possibilitam a existência de estados de presença diferenciados. As imbricações criadas na cena entre termos caros a Greenhalgh - silêncio, autoridade, presença, vulnerabilidade - determinam um tipo de atuação no qual a percepção aguda e constante de si e do outro agem na criação de um corpo performático atento, disponível e presente, no aqui-e-agora.

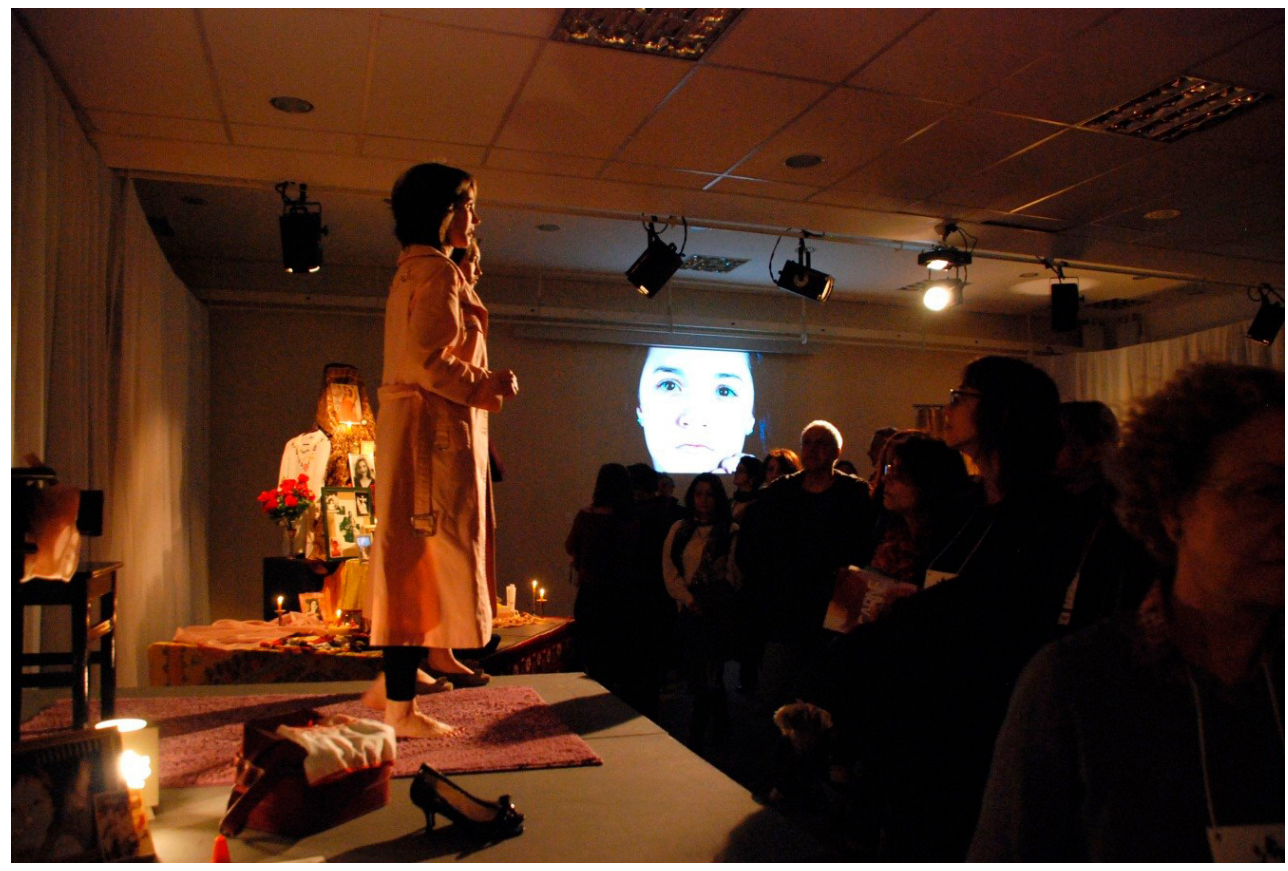

Figura 5 - Gláucia Grigolo em Dohter no Vértice Brasil, em Florianópolis - Foto: Gerusa Ansiliero

\section{Referências}

ADAMS, David. Review: The Acts - Vigia. Western Mail, Cardiff, 4 abr. 2008.

BARBA, Eugenio. A canoa de papel: Tratado de Antropologia Teatral. São Paulo, Hucitec, 1994. 
BONFITTO, Matteo. A cinética do invisível. São Paulo: Perspectiva: FAPESP, 2009.

BONFITTO, Matteo. O ator compositor: as ações físicas como eixo - de Stanislavski a Barba. São Paulo: Perspectiva, 2002.

COHEN, Renato. Work in progress na cena contemporânea. São Paulo: Perspectiva, 1998.

FERAL, Josette. Performance e performatividade: o que são os Performance Studies? In: MOSTAÇO, Edélcio et al. (org.). Sobre performatividade. Florianópolis: Letras Contemporâneas, 2009.

GREENHALGH, Jill. Depoimento pessoal em Dohter. Florianópolis, jun. 2012.

GREENHALGH, Jill. (Now) I am waiting. In: ADAMS, Gilly et. al. (org.) The Magdalena Project@25. Legacy and Challenge. Holstebro: The Open Page Publications / Odin Teatrets Forlag, 2011.

GREENHALGH, Jill. Entrevista concedida em Cardiff, ago. 2011.

GREENHALGH, Jill. Practising proximity. In: The Open Page. Women - Theatre Practice, n. 11. Holstebro: Odin Teatrets Forlag, mar 2006.

GREENHALGH, Jill. A wordy warfare. In: The Open Page. Women - Theatre - Struggle, n. 9. Holstebro: Odin Teatrets Forlag, mar 2004.

GUMBRECHT, Hans. Produção de presença. O que o sentido não consegue produzir. Rio de Janeiro: Contraponto: Ed. PUC, 2010.

HEDDON, Deirdre; MILLING, Jane. Devising performance: a critical history. New York: Palgrave Macmillan, 2006.

HELLER, Alberto Andrés. John Cage e a poética do silêncio. Florianópolis: Letras Contemporâneas, 2011.

IRIGARAY, Luce. Una nuova cultura dell'energia: Al di là di Oriente e Occidente. Torino : Bollati Boringhieri, 2011.

LEHMANN, Hans-Thies. Teatro pós-dramático. São Paulo: Cosac Naify, 2007.

QUILICl, Cassiano. Teatros do silêncio. In: Revista Sala Preta. V. 5. São Paulo: Editora da USP, 2005.

SILVA, Antônio Araújo. A encenação no coletivo: desterritorializações da função do diretor no processo colaborativo. Tese de doutorado. ECA-USP. 2008. 222p. 
SILVA, Antônio Araújo. A encenação performativa. In: Revista Sala Preta, v. 9, n. 1. São Paulo: ECA-USP, 2008a.

SONTAG, Susan. Aesthetics of silence. In: Studies or radical will. New York: Anchor Books, 1981. Disponível em: http://ebookbrowse.com/adv.php?q=Sontag+The+Aesthetics+of+Silence+pdf\&source=1 Acesso em: 10 set. 2012.

Recebido em: 29/04/2017 Aprovado em: 23/06/2017 